Check for updates

Cite this: RSC Adv., 2020, 10, 17552

Received 21st February 2020 Accepted 20th April 2020

DOI: $10.1039 / d 0 r a 01435 d$

rsc.li/rsc-advances

\section{A highly sensitive, selective and renewable carbon paste electrode based on a unique acyclic diamide ionophore for the potentiometric determination of lead ions in polluted water samples}

\author{
M. A. Zayed, (D) a Walaa H. Mahmoud, ${ }^{\text {ab }}$ Ashraf A. Abbas, ${ }^{a}$ Aya E. Ali $^{a}$ \\ and Gehad G. Mohamed*ab
}

Due to the toxicity of lead(॥) to all living organisms as it destroys the central nervous system leading to circulatory system and brain disorders, the development of effective and selective lead(I) ionophores for its detection is very important. In this work, 1,3-bis[2-( $\mathrm{N}$-morpholino)acetamidophenoxy]propane (BMAPP), belonging to acyclic diamides, was applied as a highly selective lead(॥) ionophore in a carbon paste ion selective electrode for the accurate and precise determination of $\mathrm{Pb}(I)$ ions even in the presence of other interfering ions. Factors affecting the electrode's response behavior were studied and optimized. Scanning electron microscopy (SEM), energy dispersive X-ray (EDX) and FT-IR spectroscopy were used for studying the morphology and response mechanism of the prepared sensor. The lipophilicity of the used ionophore, which contributes to the mechanical stability of the sensor, was studied using the contact angle measurement technique. The selectivity coefficients obtained by the separate solution method (SSM) and fixed interference method (FIM) confirmed the selectivity of the proposed sensor for $\mathrm{Pb}(\mathrm{II})$ ions. The proposed sensor exhibited a Nernstian slope of $29.96 \pm 0.34 \mathrm{mV}$ per decade over a wide linear range of $5 \times 10^{-8}$ to $1 \times 10^{-1} \mathrm{~mol} \mathrm{~L}-1$ and detection limit of $3 \times 10^{-8} \mathrm{~mol} \mathrm{~L}^{-1}$ for 2 months with a fast response time $(<10 \mathrm{~s})$ and working $\mathrm{pH}$ range (2.5-5.5). To further ensure the practical applicability of the sensor, it was successfully applied for the lead(॥) ion determination in different water samples and the obtained data showed an agreement with those obtained by atomic absorption spectroscopy. In addition, it was successfully applied for the potentiometric titration of $\mathrm{Pb}(॥)$ against $\mathrm{K}_{2} \mathrm{CrO}_{4}$ and $\mathrm{Na}_{2} \mathrm{SO}_{4}$.

\section{Introduction}

Among all the heavy metals, lead(II) is the most common and abundant pollutant in the environment. The permissible limit for $\mathrm{Pb}$ is $0.05 \mathrm{mg} \mathrm{\textrm {L } ^ { - 1 }}$ and if its concentration surpasses the permissible limit in water, the water becomes toxic for human usage. ${ }^{1-3}$ It is hazardous to all living creatures because it is disposed to build up in the bones if it is absorbed at a rate above $300 \mu \mathrm{g}$ per day. It has serious influences on the cardiovascular, immune, central nervous and reproductive systems. Additionally, it influences the kidney and inhibits the maturity of the nervous system, which results in possibly permanent learning and behavior disorders in children. ${ }^{\mathbf{1 , 4}}$ Moreover, lead concentrations as minute as $10 \mathrm{ppb}$ can reduce intelligence and neurological advancements and lead to many health disorders

${ }^{a}$ Chemistry Department, Faculty of Science, Cairo University, 12613, Giza, Egypt. E-mail: ggenidymohamed@sci.cu.edu.eg

${ }^{b}$ Egypt Nanotechnology Center, Cairo University, El-Sheikh Zayed, $6^{\text {th }}$ October, 12588, Giza, Egypt such as nephropathies, gastrointestinal tract alterations, reproductive dysfunction, and hemotoxic effects upon the long term exposure. ${ }^{5}$ Lead was extensively in use more than any other metal $^{6}$ but due to its severe toxicity, lead was drained away from some products such as pigments, electrical and electronic products, gasoline, and solders. ${ }^{7}$ However, its use in lead-acid batteries (LABs) despite of other innovative battery technologies was due to their maturity, cost effectiveness, safety, and applicability. ${ }^{8}$ On the other hand, LABs and the rapid growth of lead-related industries, such as lead smelting, recycling, and wire rope were the main cause of lead pollution in China resulting in common public health problems putting children's health in danger. ${ }^{\mathbf{9}, 10}$ Bearing in mind the toxic properties of lead and the rigorous regulations of its distribution, it becomes crucial to detect and determine lead in trace amounts in the environment, especially in water used for consumption and production. Moreover, the need for consistent and cost-effective analyses of lead(II) in aqueous media and organisms becomes more serious to certify environmental safety. ${ }^{3,11}$ The reported techniques for the determination of $\mathrm{Pb}$ (II) such as 
spectrophotometry, ${ }^{12,13}$ differential pulse polarography, ${ }^{14}$ spectrofluorimetry, ${ }^{15}$ and ion chromatography ${ }^{16}$ have disadvantages of high cost, which restricts their application for routine analysis. The main challenge in the ISE field is to improve the sensitivity and selectivity by searching for a suitable modifier.

Ion-selective electrodes (ISEs) are commonly used in clinical, industrial and environmental analysis. ${ }^{17}$ The relatively low cost and low maintenance make this modest design of chemical sensors advantageous over other analytical techniques. More importantly, measurements with ISEs are done in the potentiometric mode leaving the measured sample intact in means of chemical composition; thus further analysis of the same sample by other methods is possible. ${ }^{17}$ ISEs are suitable for reliable monitoring of pollutants in natural waters if the requirements of high selectivity and low detection limit are fulfilled. Taking into consideration the toxic properties of lead and rigorous regulations of its distribution, ISEs become a valuable tool for the determination of this component. ${ }^{17}$ Despite the immense effort towards obtaining ISEs devoted to the determination of the ionized lead at low concentrations in environmental samples, there is no industrially available ISE for the determination of trace concentrations of $\mathrm{Pb}^{2+} \cdot{ }^{17}$

Ion selective electrodes (ISEs) are considered important for the determination of different pollutants in the environment in a selective manner. ${ }^{18,19}$ Carbon paste electrode (CPE) is considered as a heterogeneous carbon electrode of composite nature made of graphite powder as an electrical conductor embedded in a suitable binder that provides the mechanical stability to the paste. ${ }^{20} \mathrm{CPEs}$ are characterized by low background current, ease of fabrication and their surface renewability. ${ }^{5}$ The ISE technique offers many advantages such as low cost, non-destructive analysis, portability, and quick and simple operation without any need for sample pre-treatment, ${ }^{4,21,22}$ In this research, a new carbon paste ion selective electrode modified with 1,3-bis[2- $(\mathrm{N}-$ morpholino)acetamidophenoxy]propane as an ionophore was fabricated for the selective and sensitive determination of lead ions and the electrochemical response was studied in buffered solutions of lead ( $\mathrm{pH}=4.5$, acetate buffer). Selectivity and parameters affecting the electrode response such as ionophore content, plasticizer type, $\mathrm{pH}$, temperature and response time were evaluated and optimized. The proposed sensor was utilized for the determination of $\mathrm{Pb}$ (II) in different water samples in the presence of other ions.

\section{Experimental}

\subsection{Materials and reagents}

Analytical grade reagents were used in this study. Solutions were prepared from a stock solution of $0.1 \mathrm{~mol} \mathrm{~L}^{-1} \mathrm{~Pb}(\mathrm{II})$, prepared from a sufficient quantity of lead nitrate supplied from Prolabo in bidistilled water and buffered at $\mathrm{pH}=4.5 \mathrm{using}$ acetate buffer. The working solutions were prepared daily by suitable dilution of the stock solution. All other solutions used in interference studies were prepared from analytical grade chloride salts purchased from El Nasr company. o-Nitrophenyloctyl ether ( $o$-NPOE) was supplied by Fluka, while dioctyl phthalate (DOP) and dibutyl phthalate (DBP) were supplied by
BDH. 2-Fluorophenyl-2-nitrophenyl ether (FFNE), tricresyl phosphate (TCP) and graphite powder (synthetic 1-2 $\mu \mathrm{m}$ ) were supplied by Sigma Aldrich. $\mathrm{K}_{2} \mathrm{CrO}_{4}$ and $\mathrm{Na}_{2} \mathrm{SO}_{4}$ used in the potentiometric titration were supplied by Adwick.

\subsection{Real water samples}

Different real water samples were collected. They included formation water (Amry deep (7) (sample 1) and Falak (11) (sample 2), from Western Desert, Agiba Petroleum Company, Egypt), underground tap water supplied from Manshat ElKanater network (sample 3) and river water (sample 4; the intake of Nekla station).

\subsection{Apparatus}

The potential measurements were carried out using a digital Hanna pH mV meter (model 8417). Silver-silver chloride double-junction reference electrode (HANNA, HI 5311) in conjugation with the prepared sensor under study was used. Jenway $3505 \mathrm{pH}$ meter was used for $\mathrm{pH}$ measurements. Digital burette was used for the potentiometric titration of $\mathrm{Pb}(\mathrm{II})$. Automatic pipettes (Socorex Swiss (50-200 $\mu \mathrm{L}$ and 200-1000 $\mu \mathrm{L}$ )) were used to measure the very small volumes whereas glass micropipettes were used to measure the large volumes. For surface analysis, SEM Model Quanta 250 FEG (Field Emission Gun) attached with an EDX Unit (Energy Dispersive X-ray Analyses) with accelerating voltage $30 \mathrm{KV}$, magnification $14 \times$ up to 1000000 and resolution for Gun.1n, The Egyptian Mineral Resources Authority Central Laboratories Sector, was used. The FT-IR spectra were measured on a PerkinElmer 1650 spectrometer (4000-400 $\left.\mathrm{cm}^{-1}\right)$ using the potassium bromide pellet technique at the Microanalytical Center, Cairo University, Egypt. Contact angle analyzer of model T200 manufacture by Biolin Scientific under conditions of sessile drop recipe, droplet distilled water volume $4 \mu \mathrm{m}$ and measure time $10 \mathrm{~s}$ was used.

\subsection{Procedure}

2.4.1. Preparation of the ionophore. The ionophore 1,3-bis [2-(N-morpholino)acetamidophenoxy]propane (3) (Scheme 1) was prepared in two steps as reported. ${ }^{23}$ Firstly, 1,3-bis[(2chloroacetamido)phenoxy]propane (2) was prepared by the reaction of 1,3-bis(2-aminophenoxy)propane dihydrochloride (1) with chloroacetyl chloride in DMF at $100{ }^{\circ} \mathrm{C}$ and then, a mixture of 1,3-bis(2-aminophenoxy)propane (2) and excess morpholine with few drops of triethylamine in acetone was heated under reflux for $1 \mathrm{~h}$. The solvent was then removed in vacuo. The obtained solid, which is the desired ionophore, was washed with cold water and crystallized from ethanol as colorless crystals.

2.4.2. Preparation of modified carbon paste electrodes (MCPEs). $250 \mathrm{mg}$ pure graphite powder and 5-20 mg of the prepared ionophore were transferred to a mortar and mixed well with a plasticizer $(0.1 \mathrm{~mL}$ of $o$-NPOE, TCP, DOP, DBP or FFNE). The modified paste was filled in a Teflon holder serving as the electrode body with a stainless steel rod inserted through the center of the holder for electrical contact and was kept in distilled water for $24 \mathrm{~h}$ before use. To obtain fresh surface, the 

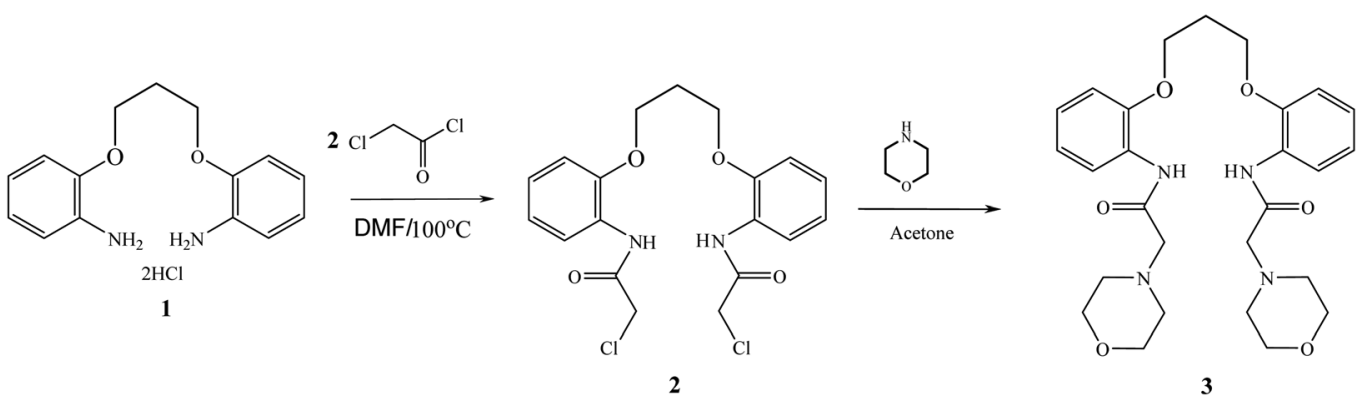

Scheme 1 Preparation of 1,3-bis[2-(N-morpholino)acetamidophenoxy]propane ionophore (3).

stainless-steel screw was pushed frontward and a new carbonpaste surface was polished on a filter paper to get a glossy novel surface. ${ }^{24}$

2.4.3. Potential measurements. In order to calibrate the newly prepared MSPEs, the prepared sensor was immersed in conjunction with a reference electrode in a $25 \mathrm{~mL}$ beaker encompassing $10 \mathrm{~mL}$ aliquot of $\mathrm{Pb}$ (II) solution $(\mathrm{pH}=4.5$, acetate buffer) having concentrations ranging from $5 \times 10^{-8}$ to $1 \times 10^{-1} \mathrm{~mol} \mathrm{~L}^{-1}$ with continuous stirring and the potential was recorded after steadying to $\pm 1 \mathrm{mV}$. Then, a calibration graph was made by plotting the recorded potentials as a function of $-\log [\mathrm{Pb}(\mathrm{II})]$. The resulting graph was used for the subsequent determination of unknown lead concentration..$^{25,26}$

2.4.4. Selectivity coefficient determination. In this work, selectivity coefficients of the electrode toward different cationic species $\left(\mathrm{M}^{n+}\right)$ were evaluated by the separate solution method (SSM), (0.001 $\mathrm{mol} \mathrm{L}^{-1}$ solutions of $\mathrm{Pb}$ (II) and interfering ions) by comparing the potential of two solutions; the selectivity coefficient was determined using the following equation: ${ }^{27}$

$$
\log K_{\mathrm{A}, \mathrm{B}}^{\mathrm{SSM}}=\left(\frac{\left(E_{\mathrm{B}}-E_{\mathrm{A}}\right) z_{\mathrm{A}} F}{R T \ln 10}\right)+\left(1-\frac{z_{\mathrm{A}}}{z_{\mathrm{B}}}\right) \log a_{\mathrm{A}}
$$

where $E_{\mathrm{A}}$ and $E_{\mathrm{B}}$ are the measured potential of $\mathrm{Pb}(\mathrm{II})$ and interfering ions, respectively; $z_{\mathrm{A}}$ and $z_{\mathrm{B}}$ are the charge numbers of the primary ion, $\mathrm{A}$, and of the interfering ion, $\mathrm{B}$; and $a_{\mathrm{A}}$ is the activity of the primary ion, A. In eqn (1), it is considered that $a_{\mathrm{A}}$ $=a_{\mathrm{B}}$ and $E_{\mathrm{A}}$ and $E_{\mathrm{B}}$ are the responses of the electrode to primary and interfering ions, respectively.

In addition, the selectivity coefficients of the interfering species were evaluated by the fixed interference method (FIM). In this manner, the MCPE and the reference electrode were placed in a $50.0 \mathrm{~mL}$ beaker containing $0.001 \mathrm{~mol} \mathrm{~L}^{-1}$ interference ion solution and the $\mathrm{Pb}$ (II) ion concentration was varied over a wide range (from $1.0 \times 10^{-9}$ to $1.0 \times 10^{-1} \mathrm{~mol} \mathrm{~L}^{-1}$ ) while the interfering ion $\left(\mathrm{M}^{n+}\right)$ concentration was kept constant. The solution was stirred magnetically and the cell potential was recorded. The $\mathrm{pH}$ of the total test solutions was constant around 4.5. The emf values obtained were plotted against the logarithm of the activity of the primary ion and the selectivity coefficient was determined using the following equation: ${ }^{28}$

$$
K_{\mathrm{A}, \mathrm{B}}^{\mathrm{FIM}}=\frac{a_{\mathrm{A}}}{\left(a_{\mathrm{B}}\right)^{z_{\mathrm{A}} / z_{\mathrm{B}}}}
$$

In eqn (2), $a_{\mathrm{A}}$ and $a_{\mathrm{B}}$ are the activities of the primary ion and the interfering ion, respectively.

2.4.5. Surface analysis. The energy dispersive X-ray analyzer (EDX) and scanning electron microscope (SEM) were used for the surface analysis of the paste at $4000 \times$ magnifications for the proposed sensor before and after interaction with lead ions.

\section{Results and discussion}

\subsection{Optimization of the carbon paste electrode components}

The ionophore based ISEs can be used to quantify more than 70 different analytes including inorganic and organic ions, and even some nonionic species like phenol derivatives and nonionic surfactants. ${ }^{29}$ This "omnivorosity" of the ionophore based ISEs is due to the large variety of the ionophores: neutral or charged lipophilic agents capable of selective binding with the respective analytes. The ion to ionophore interactions can be selective for several different reasons: the size of the analyte ion may be a perfect fit for the cavity in the ionophore structure or the functional polar groups of the ionophore may specifically bind to the analyte ion, etc. This selectivity in complexation translates into the selectivity of the potentiometric response of the electrode. The selectivity, sensitivity and response time of an ion-selective sensor is mainly related to the stability of the formed complex between the ion and ionophore..$^{30}$ As evident from scheme 1, the present ionophore has a crown ether like cavity that results in the formation of a stable chelate with two 5membered rings and one 6-membered ring between the used ionophore and lead ion resulting in a large formation constant and fast exchange kinetics that was confirmed by SEM, EDX and IR studies as will be discussed in further sections.

The amount of ionophore in the paste conformation and the properties of the pasting liquid have major influence on the selectivity, sensitivity, and linear range of the selective carbon paste electrode..$^{31}$ In case the amount of the used ionophore in the paste is adequate, a rational chemical equilibrium occurs at the electrode/solution border that is responsible for the electrode potential. However, if such material is in excess, the ratio of ionic sites to the ionophore will change, leading to substandard functioning. ${ }^{32}$ Different electrodes containing different amounts (5-20 mg) of BMAPP ionophore were prepared and calibrated with the $\mathrm{Pb}$ (II) solution and the slope was revealed. It was obvious that the optimum ionophore 
Table 1 Effect of the composition of carbon paste ingredients on the electrode performance

Composition of various components in carbon pastes (amount in $\mathrm{mg}$ )

\begin{tabular}{|c|c|c|c|c|c|c|}
\hline \multirow[b]{2}{*}{ Electrode no. } & \multicolumn{3}{|l|}{ (amount in $\mathrm{mg}$ ) } & \multicolumn{3}{|c|}{ Electrode characteristics } \\
\hline & BMAPP ionophore, $\mathrm{mg}$ & $\begin{array}{l}\text { Plasticizer (100 } \\
\mathrm{mg})\end{array}$ & Graphite, mg & $\begin{array}{l}\text { Slope } \pm \\
\text { SD, mV per decade }\end{array}$ & Linear range, $\mathrm{mol} \mathrm{L}^{-1}$ & Regression \\
\hline 1 & 5 & TCP & 250 & $31.98 \pm 0.73$ & $5 \times 10^{-7}$ to $1 \times 10^{-1}$ & 0.9990 \\
\hline 2 & 10 & TCP & 250 & $29.96 \pm 0.34$ & $5 \times 10^{-8}$ to $1 \times 10^{-1}$ & 0.9996 \\
\hline 3 & 15 & TCP & 250 & $28.53 \pm 0.84$ & $1 \times 10^{-6}$ to $1 \times 10^{-1}$ & 0.9988 \\
\hline 4 & 20 & TCP & 250 & $27.92 \pm 0.50$ & $5 \times 10^{-6}$ to $1 \times 10^{-1}$ & 0.9989 \\
\hline 5 & 10 & $o$-NPOE & 250 & $31.16 \pm 1.51$ & $5 \times 10^{-7}$ to $1 \times 10^{-1}$ & 0.9982 \\
\hline 6 & 10 & DBP & 250 & $31.05 \pm 0.62$ & $5 \times 10^{-6}$ to $1 \times 10^{-1}$ & 0.9983 \\
\hline 7 & 10 & DOP & 250 & $30.80 \pm 1.01$ & $1 \times 10^{-5}$ to $1 \times 10^{-1}$ & 0.9991 \\
\hline 8 & 10 & FFNE & 250 & $24.50 \pm 0.81$ & $1 \times 10^{-5}$ to $1 \times 10^{-1}$ & 0.9990 \\
\hline
\end{tabular}

content was found to be $10 \mathrm{mg}$ with respect to the slope, linear range and regression as indicated in Table 1.

The kind of pasting liquid (plasticizer) has a great effect on determining the carbon paste electrode characteristics because its nature affects the dielectric constant of the carbon paste and the mobility of the ions. In addition, it enables homogenous solubilization and modification of the distribution constant of the used ionophore. ${ }^{30,33}$ In the investigation for a suitable plasticizer, five plasticizers, namely, TCP, $o$ NPOE, DOP, DBP and FFNE, were used in sample electrodes to figure out the plasticizer with the best response. It was found that TCP as a solvent mediator produced the best response with respect to the slope, linear range, repeatability and regression as shown in Table 1. Electrode no. 2 has been chosen for further study.

\subsection{Selectivity studies}

The ionophore has the major control on the selectivity of an ISE membrane. The affinity between the analyte and the ionophore and the ion-split between two immiscible phases establish the base mechanism of the potentiometric ion

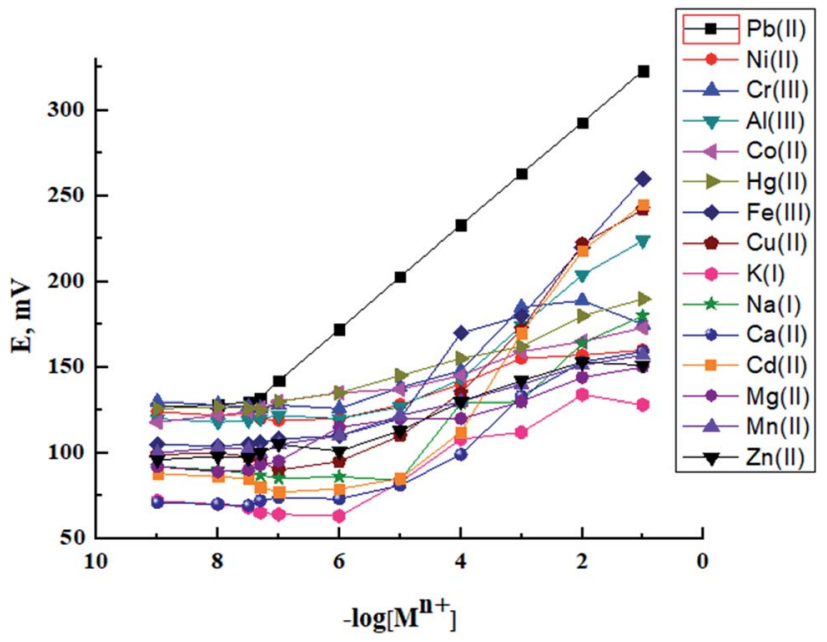

Fig. 1 Potential response of the proposed sensor for different metal ions. sensors. ${ }^{34}$ In preliminary experiments, BMAPP ionophore was applied for the preparation of carbon paste electrodes of the same composition as electrode no. 2, given in Table 1, for a variety of metal ions and their potential responses are shown in Fig. 1. It was established that among all the investigated cations, $\mathrm{Pb}$ (II) ion showed the Nernstian potential response over a wide concentration range and this can be assigned to the selective behavior and more interaction of the ionophore with $\mathrm{Pb}$ (II) over other metal ions as well as the fast exchange kinetics of the resulting complex. ${ }^{35,36}$ In addition, the dissimilarities in the ionic size and the permeability of the tested ions hinder their interference. ${ }^{37}$

In this work, selectivity coefficients of the proposed electrode towards different cationic species $\left(\mathrm{M}^{n+}\right)$ were evaluated by using both of the separate solution method (SSM), $\left(0.001 \mathrm{~mol} \mathrm{~L}^{-1}\right.$ of $\mathrm{Pb}$ (II) and interfering ions $)^{31,38}$ and the fixed interference method (FIM) where selectivity coefficients were evaluated graphically from potential measurements in solutions containing $0.001 \mathrm{~mol} \mathrm{~L}^{-1}$ of the interfering ions and varying concentrations of $\mathrm{Pb}$ (II) ions. ${ }^{32,39}$ The measured selectivity coefficients are given in Table 2 . It can be seen that the selectivity coefficient values are much smaller than 1.0 , which indicate a good discrimination of the proposed sensor for $\mathrm{Pb}$ (II) ions from the other metal ions.

Table 2 Selectivity coefficients of the $\mathrm{Pb}(\|)$ sensor in presence of other ions

\begin{tabular}{lll}
\hline Foreign ion & $K_{\mathrm{Pb}(\mathrm{II}), \mathrm{B}}^{\mathrm{SM}}$ & $K_{\mathrm{Pb}(\mathrm{II}), \mathrm{B}}^{\mathrm{FM}}$ \\
\hline $\mathrm{Ni}^{2+}$ & $3.13 \times 10^{-4}$ & \\
$\mathrm{Cd}^{2+}$ & $9.91 \times 10^{-4}$ & $3.16 \times 10^{-4}$ \\
$\mathrm{Co}^{2+}$ & $4.25 \times 10^{-4}$ & $4.83 \times 10^{-3}$ \\
$\mathrm{Cu}^{2+}$ & $9.90 \times 10^{-4}$ & $9.25 \times 10^{-4}$ \\
$\mathrm{Mn}^{2+}$ & $9.88 \times 10^{-5}$ & $2.24 \times 10^{-4}$ \\
$\mathrm{Zn}^{2+}$ & $1.15 \times 10^{-4}$ & $8.53 \times 10^{-5}$ \\
$\mathrm{Cr}^{3+}$ & $3.14 \times 10^{-4}$ & $9.95 \times 10^{-5}$ \\
$\mathrm{Al}^{3+}$ & $1.35 \times 10^{-4}$ & $3.01 \times 10^{-5}$ \\
$\mathrm{Fe}^{3+}$ & $2.14 \times 10^{-4}$ & $1.60 \times 10^{-4}$ \\
$\mathrm{Hg}^{2+}$ & $7.94 \times 10^{-4}$ & $1.58 \times 10^{-4}$ \\
$\mathrm{Ca}^{2+}$ & $5.77 \times 10^{-5}$ & $9.65 \times 10^{-4}$ \\
$\mathrm{Mg}^{2+}$ & $4.58 \times 10^{-5}$ & $5.01 \times 10^{-4}$ \\
$\mathrm{Na}^{+}$ & $4.60 \times 10^{-2}$ & $8.03 \times 10^{-5}$ \\
$\mathrm{~K}^{+}$ & $1.14 \times 10^{-2}$ & $8.01 \times 10^{-2}$ \\
& & $7.89 \times 10^{-2}$
\end{tabular}




\subsection{SEM, EDX and IR analyses}

The performance of a modified carbon paste electrode depends on the selective extraction of the target ion with the aid of the plasticizer. The response mechanism may be attributed to the complex formation at the sensor surface by the extraction of $\mathrm{Pb}$ (II) ions from the solution into the paste of a suitable modifier content and plasticizer during the measurement. ${ }^{40}$ This stability was also confirmed by SEM, EDX and IR studies. In an attempt to relate the potentiometric response to surface morphology, energy dispersive X-ray analysis (EDX) and scanning electron microscopy (SEM), which is considered as an important technique to illustrate the surface morphology of sensors, ${ }^{\mathbf{4 1 - 4 4}}$ were used.

The proposed sensor was prepared according to its optimum composition and then soaked in $10^{-3} \mathrm{~mol} \mathrm{L^{-1 }}$ of lead ion solution for 1 hour. As shown in Fig. 2, the sensor surface is homogeneous and permeable and includes grains that facilitate the $\mathrm{Pb}$ (II) ion diffusion, which is proved by the development of illuminated spots filling the cavities between these carbon grains and alteration of surface morphology after soaking and can be explained by the complex formation between the $\mathrm{Pb}$ (II) ions and the used modifier. This mechanism was also supported by EDX analysis, which gave quantitative information about the surface composition as shown in Fig. 3. IR spectra confirmed these data. It was revealed that the absorption $(\mathrm{NH})$ band at $3271 \mathrm{~cm}^{-1}$ was shifted to $3250 \mathrm{~cm}^{-1}$ and the etheric oxygen band was shifted to a lower frequency from $1165 \mathrm{~cm}^{-1}$ to $1149 \mathrm{~cm}^{-1}$ while the other ionophore band positions remained unchanged, which in turn confirmed the complex formation between $\mathrm{Pb}$ (II) ion and the used ionophore through coordination via the $\mathrm{NH}$ and etheric oxygens.

\section{4. $\quad$ Effect of pH}

As illustrated in Fig. 4, the response of the proposed sensor at $1.0 \times 10^{-5}$ and $1 \times 10^{-3} \mathrm{~mol} \mathrm{~L}^{-1}$ of $\mathrm{Pb}$ (II) ion at different $\mathrm{pH}$ values was studied. Dilute $\mathrm{NaOH} / \mathrm{HNO}_{3}$ solutions were used to adjust the solution $\mathrm{pH}$. The electrode response was $\mathrm{pH}$ independent in the range of 2.5-5.5. At a $\mathrm{pH}$ higher than 5.5, the
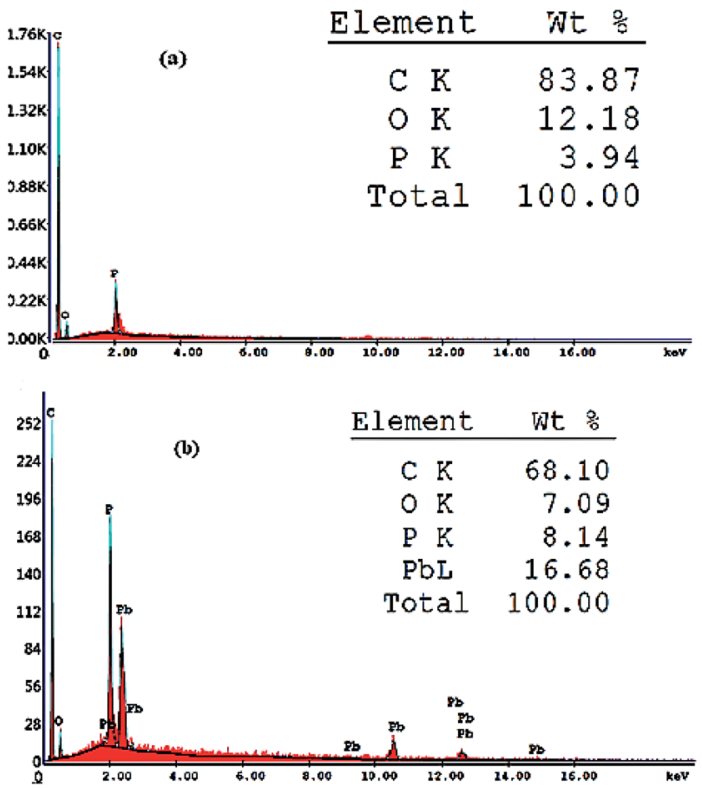

Fig. 3 EDX analysis showing weight\% of different elements present in the proposed sensor (a) before and (b) after soaking in $1.0 \times$ $10^{-3} \mathrm{~mol} \mathrm{~L}{ }^{-1} \mathrm{~Pb}(॥)$ ion solution for $1 \mathrm{~h}$ at $25^{\circ} \mathrm{C}$.

hydrolysis of lead ions into lead hydroxide $\left(K_{\mathrm{sp}}=1.42 \times 10^{-20}\right)$ took place, which decreased the potentiometric response considerably. On the other hand, at a pH lower than $2.5, \mathrm{H}^{+}$ions can replace the $\mathrm{Pb}$ (II) ions and cause interference by ligand protonation at such high concentration of hydrogen ions. ${ }^{\mathbf{1 8 , 4 5}}$

\subsection{Response time and reversibility}

Dynamic response time, which is defined as the average time required for a sensor to reach potential within $\pm 1 \mathrm{mV}$ of the final equilibrium value, is an important factor for any sensor. The critical emf response of the electrode was assessed according to IUPAC recommendations. ${ }^{46}$ As shown in Fig. 5, it is evident that the response time of the proposed sensor was less than $10 \mathrm{~s}$ for $\mathrm{Pb}$ (II) concentrations in the range of $5.0 \times 10^{-8}$ to
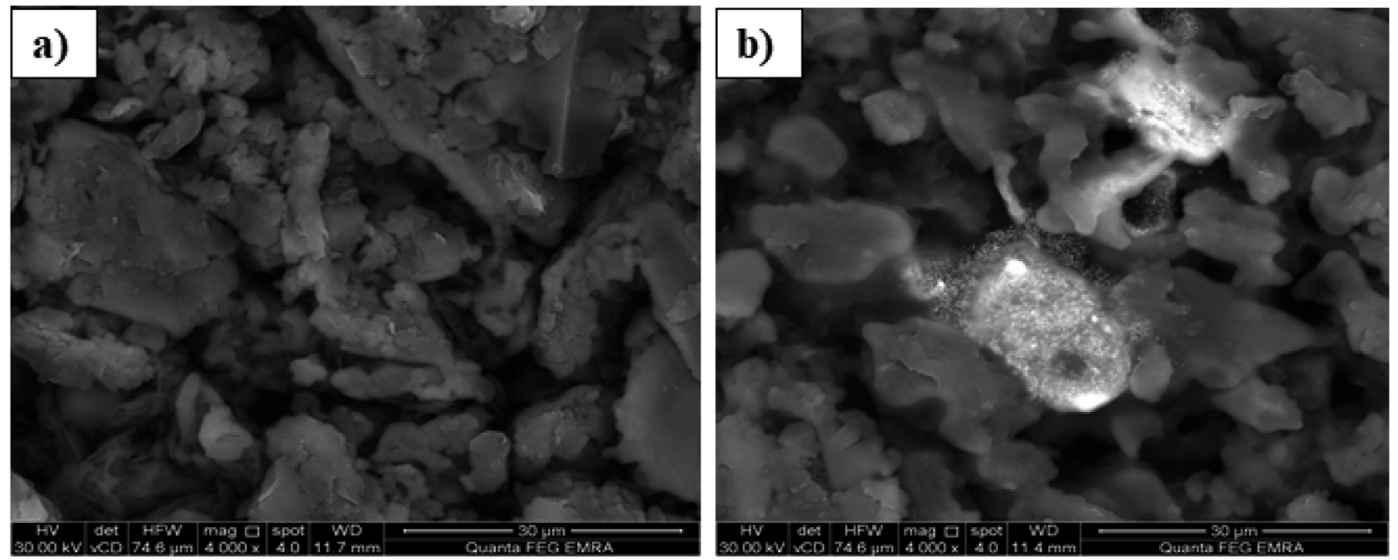

Fig. 2 SEM image of the surface of the proposed sensor (250 mg graphite, $100 \mathrm{mg}$ TCP and $10 \mathrm{mg}$ BMAPP ionophore) (a) before and (b) after soaking in $1.0 \times 10^{-3} \mathrm{~mol} \mathrm{~L}-1 \mathrm{~Pb}(I)$ ion for $1 \mathrm{~h}$ at $25^{\circ} \mathrm{C}$. 


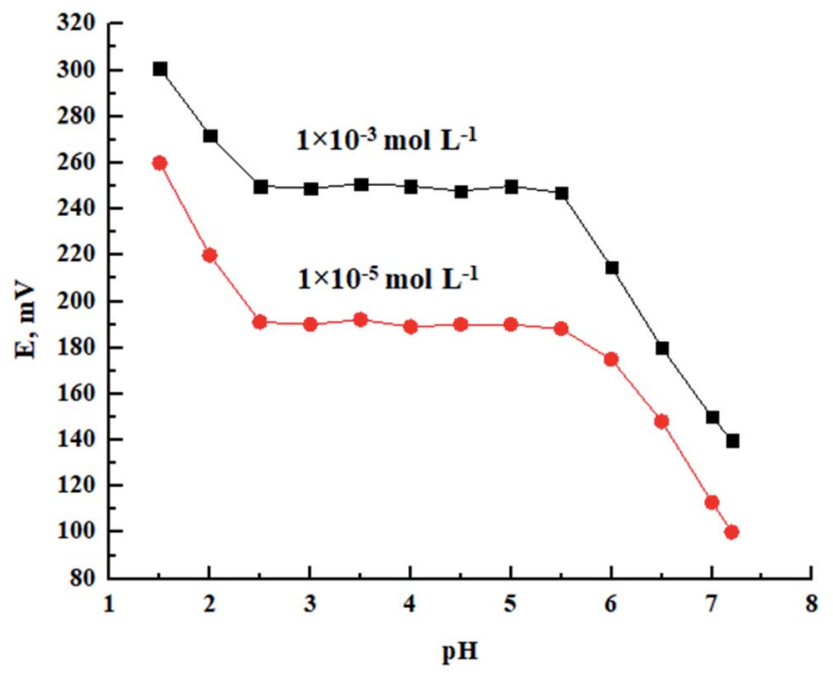

Fig. 4 Effect of $\mathrm{pH}$ at two different $\mathrm{Pb}(\mathrm{II})$ concentrations on the potentiometric response of the proposed $\mathrm{Pb}(॥)$ sensor.

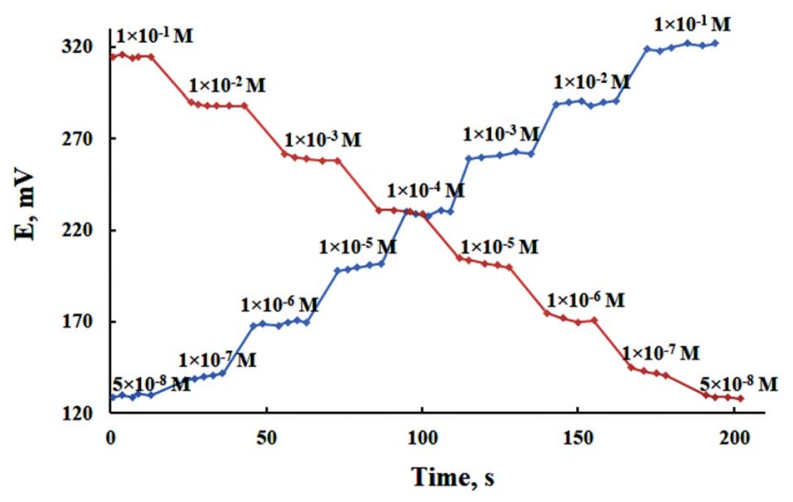

Fig. 5 Dynamic response of the proposed MCPE for step changes of $\mathrm{Pb}($ ॥) concentration from low-to-high and high-to-low.

$1.0 \times 10^{-1} \mathrm{~mol} \mathrm{~L}^{-1}$ with response stability up to $5 \mathrm{~min}$. In order to study the reversibility of the used MCPE, the potential was recorded in the sequence of high-to-low concentrations of $\mathrm{Pb}$ (II) ion. The results shown in Fig. 5 revealed that the potential response was reversible and these observations implied that no memory effect on the electrode response was noticed. ${ }^{47}$

\subsection{Effect of temperature}

In order to study the influence of temperature on the EMF response of the proposed sensor, calibration curves were constructed at different temperatures covering the range $10-70{ }^{\circ} \mathrm{C}$. As shown in Table 3, the slope of the calibration graph of the proposed sensor was Nernstian up to $60{ }^{\circ} \mathrm{C}$ of the test solution and the linear concentration range was almost unchanged, which means that the investigated electrode can be used up to $60{ }^{\circ} \mathrm{C}$ without noticeable deviation from the Nernstian behavior. However, temperatures higher than $60{ }^{\circ} \mathrm{C}$ caused a significant deviation from the theoretical values and this can be attributed to a damage of the electrode surface caused by some leaching in
Table 3 Effect of temperature on the potentiometric response of the proposed $\mathrm{Pb}(॥)$ sensor

\begin{tabular}{llll}
\hline $\begin{array}{l}T \\
\left({ }^{\circ} \mathrm{C}\right)\end{array}$ & $\begin{array}{l}\text { Slope } \\
(\mathrm{mV} \text { per decade) }\end{array}$ & $\begin{array}{l}\text { Linear range } \\
\left(\mathrm{mol} \mathrm{L}^{-1}\right)\end{array}$ & $R^{2}$ \\
\hline 10 & 30.68 & $5 \times 10^{-8}$ to $1 \times 10^{-1}$ & 0.9991 \\
20 & 30.43 & $5 \times 10^{-8}$ to $1 \times 10^{-1}$ & 0.9997 \\
30 & 29.61 & $5 \times 10^{-8}$ to $1 \times 10^{-1}$ & 0.9996 \\
40 & 29.54 & $5 \times 10^{-8}$ to $1 \times 10^{-1}$ & 0.9997 \\
50 & 28.14 & $5 \times 10^{-8}$ to $1 \times 10^{-1}$ & 0.9992 \\
60 & 27.04 & $5 \times 10^{-8}$ to $1 \times 10^{-1}$ & 0.9991 \\
70 & 19.89 & $1 \times 10^{-6}$ to $1 \times 10^{-1}$ & 0.9912
\end{tabular}

the paste matrix lowering the response. ${ }^{48}$ To calculate the isothermal coefficient $\left(\mathrm{d} E^{\circ} / \mathrm{d} t\right)$ cell of the cell, the standard cell potentials, $E_{\text {cell }}^{\circ}$, were determined at different temperatures from the respective calibration graphs as the intercept of these plots at $-\log \left[\mathrm{Pb}(\mathrm{II}), \mathrm{mol} \mathrm{L}^{-1}\right]=0$ and were plotted versus $(t-25)$, where $t$ was the temperature of the test solution in ${ }^{\circ} \mathrm{C}$ applying Antropov's equation. ${ }^{24-26,33,40}$ The isothermal coefficient value was $6.1 \times 10^{-5} \mathrm{~V}^{\circ} \mathrm{C}^{-1}$, which is a small value revealing the high thermal stability of the studied sensor within the investigated temperature range.

\subsection{Ionophore lipophilicity, lifetime, homogeneity, reproducibility and detection limit}

Constant potentials and long lifetime depend mainly on the lipophilicity and good solubility of the used ionophore in the paste matrix, which ensures the absence of any ionophore leaching. ${ }^{49}$ As shown in Fig. 6, contact angle measurement was used to measure the ionophore lipophilicity and the average contact angle was $137.086^{\circ}$, which is much larger than $90^{\circ}$ corresponding to low wettablility i.e., lipophilicity of the used ionophore. ${ }^{50}$ It was observed that the paste could be in use for a period of two months without significant deviation from the Nernstian behaviour. The surface of the MCPE was renewed by polishing it on a filter paper before calibration. It was also rinsed carefully in distilled water to remove the memory effects. $^{40}$

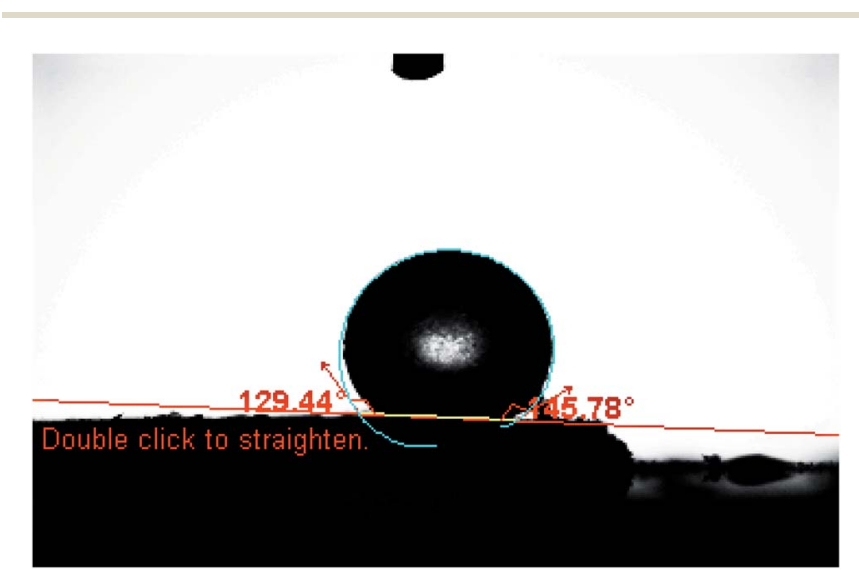

Fig. 6 Contact angle formed by a sessile water drop on a smooth homogenous surface of the used ionophore. 
To test the paste homogeneity, the proposed electrode was applied for $\mathrm{Pb}$ (II) measurement in a $1.0 \times 10^{-3} \mathrm{~mol} \mathrm{~L}^{-1} \mathrm{~Pb}$ (II) solution. The measurement was repeated five times and after each measurement the electrode surface was renewed by squeezing a little carbon paste out of the holder and a fresh surface was smoothed on a piece of weighing paper. The average potential was $265 \mathrm{mV}$ with a RSD\% value of 0.95 , which was reasonable.

On the other hand, to evaluate the reproducibility of the proposed sensor, a series of pastes (five) with the optimum composition, as shown in Table 1, was prepared and the responses of the prepared electrodes were tested for $\mathrm{Pb}(\mathrm{II})$ ion concentration of $1.0 \times 10^{-3} \mathrm{~mol} \mathrm{~L}^{-1}$. The results showed that the proposed electrodes have good reproducibility with a RSD\% value of 1.98. The limit of detection, which was evaluated according to the IUPAC recommendations ${ }^{46}$ was found to be 3.0 $\times 10^{-8} \mathrm{~mol} \mathrm{~L}^{-1}$ for $\mathrm{Pb}(\mathrm{II})$ ions.

\subsection{Analytical application}

The concentration of $\mathrm{Pb}$ (II) was measured in real water samples including formation water, underground tap water, river water and sea water samples. The $\mathrm{pH}$ of each sample was adjusted by $\mathrm{NaOH}$ and $\mathrm{HNO}_{3}$ to the desired pH. An aliquot of standard solutions was added to the sample and the $\mathrm{Pb}$ (II) concentrations were determined. Table 4 summarizes the results obtained for all the water samples and the recovery\% for the applied electrode was satisfactory, in spite of the presence of other cations, because of the high selectivity and low detection limit of the constructed $\mathrm{Pb}$ (II) sensor. A very good correspondence between the spiked and experimentally obtained results was observed.

In addition, as shown in Fig. 7, the proposed sensor was used successfully as an indicator electrode in the potentiometric titration of $5 \mathrm{~mL}$ of $1.0 \times 10^{-2} \mathrm{~mol} \mathrm{~L}^{-1} \mathrm{~Pb}$ (II) solution, adjusted at $\mathrm{pH}=4.5$ using acetate buffer, against standard solutions of $1.0 \times 10^{-2} \mathrm{~mol} \mathrm{~L}^{-1} \mathrm{~K}_{2} \mathrm{CrO}_{4}$ and $\mathrm{Na}_{2} \mathrm{SO}_{4}$.

\subsection{Comparative study}

The main performance characteristics (linear range, detection limit, lifetime, working $\mathrm{pH}$, slope and selectivity) of some of the lead-selective electrodes from the literature ${ }^{51-56}$ against the data of the proposed lead ISEs are listed in Table 5. As can be seen, the proposed lead-selective electrode exhibited improved characteristics of response such as concentration range, detection limit, selectivity coefficients for potential interfering ions (especially for $\mathrm{Hg}$ (II), which was considered as a main interferent in the previously reported $\mathrm{Pb}$ (II) ISEs) and response time. However, they have nearly the same Nernstian slopes and working $\mathrm{pH}$ ranges. In addition, all of the listed electrodes are based on the PVC membrane, which suffers from increased

Table 4 Determination of lead(॥) in spiked water samples and the comparison of the results with those obtained by ICP-AAS

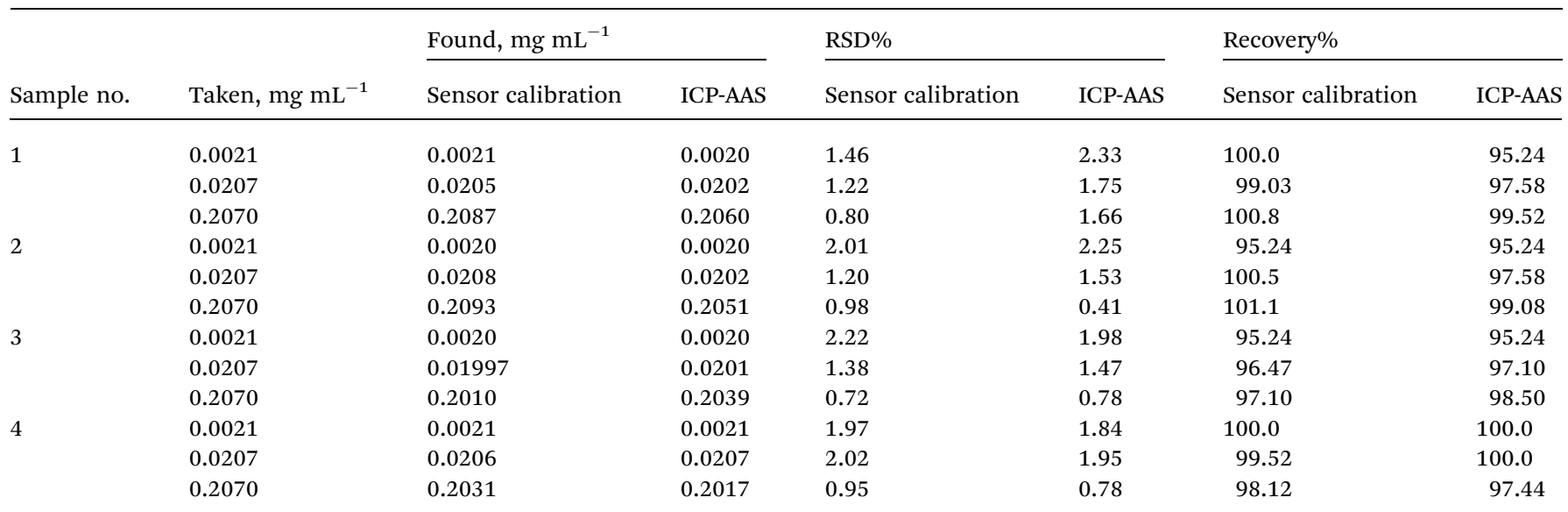
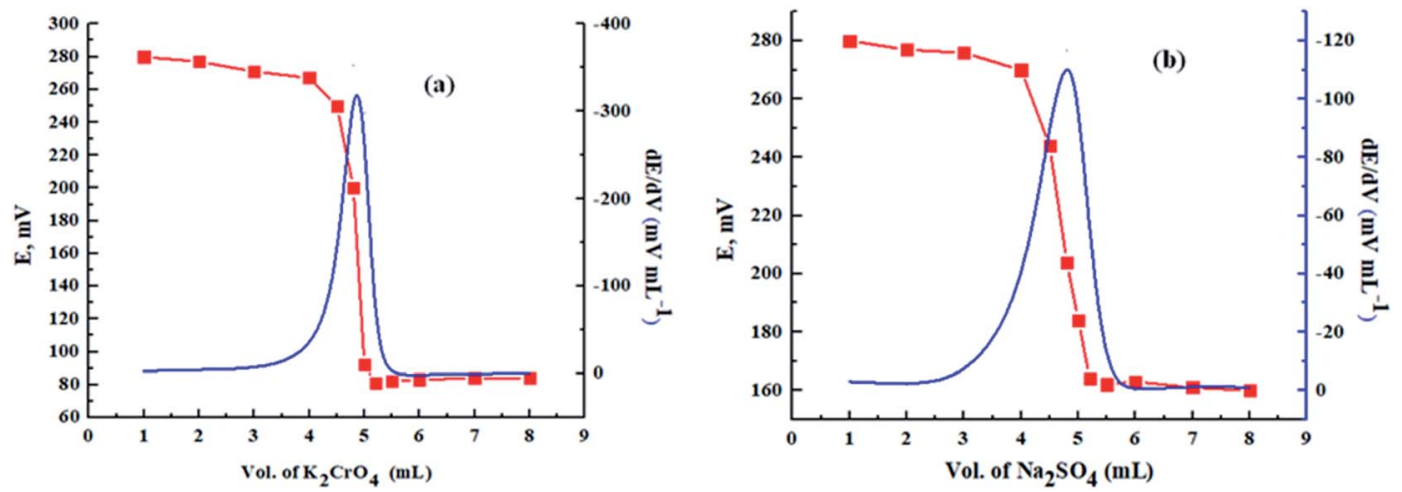

Fig. 7 S-shape and first derivative titration curves for the potentiometric titration of $5.0 \mathrm{~mL}\left(1.0 \times 10^{-2}\right) \mathrm{mol} \mathrm{L}^{-1} \mathrm{~Pb}\left(\mathrm{NO}_{3}\right)_{2}$ solution against (a) 1.0 $\times 10^{-2} \mathrm{~mol} \mathrm{~L}^{-1}$ of $\mathrm{K}_{2} \mathrm{CrO}_{4}$ and (b) $1.0 \times 10^{-2} \mathrm{~mol} \mathrm{~L}^{-1}$ of $\mathrm{Na}_{2} \mathrm{SO}_{4}$. 




system impedance and the electrode response time..$^{57}$ This work is based on carbon paste potentiometric electrode which is simple, cheap and renewable. So, it is apparent that this electrode is superior to previously reported electrodes in most cases as it can be used in a wider concentration range with an enhanced sensitivity and selectivity for $\mathrm{Pb}$ (II) ions from a wide variety of other heavy metal ions (which is more proper for industrial samples) with a very fast response time and a fairly long lifetime. It must be noted that there are voltammetric and fluorescent sensors ${ }^{58,59}$ that show enhanced selectivity and sensitivity in the determination of $\mathrm{Pb}$ (II) ions, but they are to some extent expensive and complicated.

\section{Conclusion}

A new $\mathrm{Pb}$ (II) ion selective carbon paste electrode was developed by simple incorporation of 1,3 -bis[2-( $N$-morpholino)acetamidophenoxy]propane as an ionophore. It was found that the proposed sensor showed an enhancement in the performance of the $\mathrm{Pb}$ (II) ISE in comparison to the other previously reported electrodes. This simple and easily fabricated $\mathrm{Pb}$ (II) sensor can serve as an indicator electrode in the potentiometric titration of $\mathrm{Pb}$ (II) against $\mathrm{K}_{2} \mathrm{CrO}_{4}$ and $\mathrm{Na}_{2} \mathrm{SO}_{4}$ and can also be used to establish $\mathrm{Pb}$ (II) ion concentration in real water samples containing various interfering metal ions in a selective and sensitive manner.

\section{Conflicts of interest}

There are no conflicts to declare.

\section{References}

1 T. Arfin and A. Tarannum, J. Membr. Sci., 2019, 7, 102811102820.

2 H. L. Needleman and D. Bellinger, Annu. Rev. Public Health, 1991, 12, 111-140.

3 M. R. Huang, Y. B. Ding and X. G. Li, Analyst, 2013, 138, 3820-3829.

4 R. Hussain, M. Q. Khan and A. A. Khan, Groundwater for Sustainable Development, 2019, 8, 216-225.

5 Y. Wang, Y. Wu, J. Xie and X. Hu, Sens. Actuators, B, 2013, 177, 1161-1166.

6 D. L. Heskel, Curr. Anthropol., 1983, 24, 362-366.

7 N. Mansson, B. Bergback and L. Sorme, J. Ind. Ecol., 2009, 13, 94-111.

8 W. Liu, J. Tian, L. Chen and Y. Guo, Environ. Pollut., 2017, 220, 696-703.

9 K. Chen, L. Huang, B. Yan, H. Li, H. Sun and J. Bi, Environ. Sci. Technol., 2014, 48, 12930-12936.

10 Y. Lv, T. Sun and W. Rang, Chin. Prev. Med., 2013, 14, 868870.

11 Y. Liu, Y. Liu, Y. Gao and P. Wang, Sens. Actuators, B, 2019, 281, 705-712.

12 H. Ebrahimzadeh, A. A. Asgharinezhad, E. Moazzen, M. M. Amini and O. Sadeghi, J. Food Compos. Anal., 2015, 41, 74-80. 
13 Y. Xiang, L. Mei and A. Tong, Anal. Chim. Acta, 2007, 581, 132-136.

14 A. Bazzi, B. Kreuz, J. Wuokila and A. Maqboul, J. Chem. Educ., 2005, 82, 435-438.

15 A. K. Tyagi, J. Ramkumar and O. D. Jayakumar, Analyst, 2012, 137, 760-764.

16 J. A. Cox, J. L. West and P. J. Kulesza, Analyst, 1984, 109, 927930.

17 M. Guzinski, G. Lisak, J. Kupis, A. Jasinski and M. Bochenska, Anal. Chim. Acta, 2013, 791, 1-12.

18 A. Jasiński, M. Guziński, G. Lisak, J. Bobacka and M. Bocheńska, Sens. Actuators, B, 2015, 218, 25-30.

19 G. Lisak, T. Sokalski, J. Bobacka, L. Harju, K. Mikhelson and A. Lewenstam, Anal. Chim. Acta, 2011, 707, 1-6.

20 P. Fanjul-Bolado, D. Hernandez-Santos, P. J. LamasArdisana, A. Martın- Pernıa and A. Costa-Garcia, Electrochim. Acta, 2008, 53, 3635-3642.

21 Z. Lu, X. Lin, J. Zhang, W. Dai, B. Liu, G. Mo, J. Ye and J. Ye, Electrochim. Acta, 2019, 295, 514-523.

22 C. Liu, X. Jiang, Y. Zhao, W. Jiang, Z. Zhang and L. Yu, Electrochim. Acta, 2017, 231, 53-60.

23 A. A. Abbas, Synthesis, 2004, 3, 419-428.

24 T. A. Ali, G. G. Mohamed and A. H. Farag, Int. J. Electrochem. Sci., 2015, 10, 564-578.

25 T. A. Ali, G. G. Mohamed and H. A. Said, Chem. Eng. Commun., 2016, 203, 724-735.

26 T. A. Ali, G. G. Mohamed, E. M. S. Azzam and A. A. Abd-Elaal, Sens. Actuators, B, 2014, 191, 192-203.

27 S. Kamata, A. Bhale, Y. Fukunaga and A. Murata, Anal. Chem., 1998, 60, 2464-2467.

28 B. Rebary, P. Paul and P. K. Ghosh, Food Chem., 2010, 123, 529-534.

29 I. A. Pechenkina and K. N. Mikhelson, Russ. J. Electrochem., 2015, 51(2), 93-102.

30 H. Khani, M. K. Rofouei, P. Arab, V. K. Gupta and Z. Vafaei, J. Hazard. Mater., 2010, 183, 402-409.

31 A. Soleymanpour and M. Ghasemian, Measurement, 2015, 14-20.

32 T. A. Ali, G. G. Mohamed, M. M. Omar and N. M. Hanafy, J. Ind. Eng. Chem., 2017, 47, 102-111.

33 M. A. A. Perez, L. P. Marin, J. C. Quintana and M. Y. Pedram, Sens. Actuators, B, 2003, 89, 262-268.

$34 \mathrm{H}$. H. Girault, Electrochemistry at liquid-liquid interfaces, in Electroanalytical Chemistry, ed. A. J.Bard, C. G.Zoski, Taylor \& Francis, Boca Raton, 2010, vol. 23, p. 1.

35 R. K. Mahajan and P. Sood, Int. J. Electrochem. Sci., 2007, 2, 832-847.

36 M. Shamsipur, S. Y. Kazemi and H. Shargi, Sensors, 2007, 7, 438-447.
37 E. Bakker, P. Buhlmann and E. Pretsch, Chem. Rev., 1997, 97, 3083-3132.

38 Y. Umezawa, K. Umezawa and H. Sato, Pure Appl. Chem., 1995, 67, 507-518.

39 V. K. Gupta, B. Sethi, R. A. Sharma, S. Agarwal and A. Bharti, J. Mol. Liq., 2013, 177, 114-118.

40 R. F. Aglan, G. G. Mohamed and H. A. Mohamed, J. Pharm. Res., 2012, 5, 4748-4754.

41 M. A. Deshmukh, R. Celiesiute, A. Ramanaviciene, M. D. Shirsat and A. Ramanavicius, Electrochim. Acta, 2018, 259, 930-938.

42 S. A. R. Ivari, A. Darroudi, M. H. A. Zavar, G. Zohuri and N. Ashraf, Arabian J. Chem., 2017, 10, s864-s869.

43 M. Rezayi, L. Y. Heng, A. Kassim, S. Ahmadzadeh, Y. Abdollahi and H. Jahangirian, Sensors, 2012, 12, 88068814.

44 M. Ghaedi, S. Naderi, M. Montazerozohori, F. Taghizadeh and A. Asghari, Arabian J. Chem., 2017, 10, s2934-s2943.

45 M. M. Ardakani, M. K. Kashani, M. Kashani and A. A. Ensafi, Sens. Actuators, B, 2005, 107, 438-445.

46 IUPAC, Analytical chemistry division, commission on analytical electrodes, Pure Appl. Chem., 1979, 48, 127-131.

47 E. Y. Z. Frag, M. E. Mohamed, A. E. Ali and G. G. Mohamed, Ind. J. Chem. A, 2020, 59, 162-173.

48 H. M. Abu Shawish, M. Elhabiby, H. S. Abu Aziz, S. M. Saadeh and A. Tbaza, Sens. Actuators, B, 2016, 235, 18-26.

49 V. K. Gupta, L. P. Singh, R. Singh, N. Upadhyay, S. P. Kaur and B. Sethi, J. Mol. Liq., 2012, 164, 11-16.

50 Y. Yuan and T. R. Lee, Contact Angle and Wetting Properties, in Surface Science Techniques Springer Series, Surface Sciences, ed. G.Bracco and B.Holst, Springer Berlin Heidelberg, Berlin and Heidelberg, 2013, vol. 51, pp. 3-34.

51 M. R. Huang, X. W. Rao, X. G. Li and Y. B. Ding, Talanta, 2011, 85, 1575-1584.

52 D. Wilson, M. A. Arada, S. Alegret and M. Valle, J. Hazard. Mater., 2010, 181, 140-146.

53 X. G. Li, X. L. Ma and M. R. Huang, Talanta, 2009, 78, 498505.

54 A. Abbaspour, E. Mirahmadi, A. Khalafi-nejad and S. Babamohammadi, J. Hazard. Mater., 2010, 174, 656-661.

55 H. R. Zare, M. M. Ardakani, N. Nasirizadeh and J. Safari, Bull. Korean Chem. Soc., 2005, 26, 51-56.

56 M. R. Yaftian, S. Rayati, D. Emadi and D. Matt, Anal. Sci., 2006, 22, 1075-1078.

57 B. Muller and P. C. Hauser, Anal. Chim. Acta, 1996, 320, 6975.

58 X. Luo, W. Huang, Q. Shi, W. Xu, Y. Luan, Y. Yang, H. Wang and W. Yang, RSC Adv., 2017, 7, 16033-16040.

59 T. Lan, K. Furuya and Y. Lu, Chem. Commun, 2010, 46, 38963898. 